There is no doubt that the standard of taxonomy needs to be raised aloft. Looking back over a period. of twenty years, during which he has been in charge of a great systematic institution, Mr. Cotton has become acutely conscious of the need of recruits to this branch of biology. Unless such recruits be forthcoming, and in considerable numbers, the immense floras and faunas of the world can never be properly understood. Only those who have worked with such world floras and faunas have any conception of their magnitude and their riches in genera and species.

Ecology and cytology naturally make a strong appeal also to the present-day student not only on account of their intrinsic interest but also because of their suitability for short-term research and research theses: but their very interest and glamour is apt to lead to the less exciting, more exacting, but all-important work of taxonomy being passed by. It may even fall into disrepute among those who do not realize the value of taxonomy, or who think only in terms of nineteenth-century systematics. Mr. Cotton therefore appealed to the young biologist to consider seriously the claims of this branch of science. There can be no question of the need for a greater number of professional taxonomists. The flora or handbook which the ecologist or economic botanist demands when he takes up a Colonial appointment can only be prepared after years of patient labour in a systematic institution, while more fortunate colleagues who carry out researches on such subjects as physiology and genetics require correctly named material or they may find their results at variance with those of other workers.

Mr. Cotton pointed out that this emphasis on the importance of taxonomy was not made on account of personal preference but from a sense of responsibility and a desire to serve the interests of biologists as a whole.

201

\section{METHODS AND RESULTS OF} NUTRITION SURVEYS

TN Octo $19 \%$, the Nutrition Society set up a I Standing Autvisory Committee "for co-ordination of method of survey in liberated territories". Advantage rads taken of the fact that there was in Brijosin at that time a large number of scientific wofkers from enemy-occupied countries, and three representative panels were set up to report on : (1) laboratory methods; (2) clinical methods; (3) methods of survey of food consumption.

Certainly some agreement on terminology, methods of investigation and ways of presenting results is badly needed, particularly for the first two. As things stand, it is difficult to compare one person's findings with another's, with any assurance that the measurements made do, in fact, provide a true basis for comparison.

Two of the three panels (the first and the third) presented reports in August 1945*. It would be very valuable if the Nutrition Society would now add a short note on the experiences since gained by investigators while putting the recommendations

* Standing Advisory Committee for Co-ordination of Methods of Survey in Liberated Territories. Recommendations with Regard to Methods of Investigation of Nutrition. Pp. 67. Dietary Panel : Methods for Dietary Survey. Pp. 23. (London: Bureau of Nutrition Surveys, London Hospital, E.1, 1945.) into practice. Has any modification been required, and if so, what? Have any other techniques been evolved or found more practicable?

Choice of method for any investigation is inevitably limited by the facilities available. The Laboratory Methods Panel has recognized this and has limited its recommendations accordingly. Estimations of hæmoglobin and of proteins in plasma or serum are dealt with very fully, and tests of vitamin $\mathrm{C}$ status are described; but comment on "the assessment of level of nutrition with regard to B-vitamins" is limited to a short description of the principles and relevant literature, since "the biochemical evaluation of the nutritional status of the B-vitamins requires elaborate equipment and special chemicals".

It appears that the main difficulties in reaching any uniformity of meaning in past surveys have been due to : (1) differences in methods used ; (2) differences in assumptions on which calculations were based; (3) differences in standards used; (4) personal factors; (5) errors in instruments; (6) differences in methods of expressing results.

Accordingly, among the recommendations made, the Panel suggests : (1) that apparatus used should be standardized ; (2) that results should be expressed in absolute units and in the decimal system; (3) that methods in which subjective errors may be large should be avoided.

In addition to critical reviews of estimation methods mentioned above, there are "general recommendations with regard to taking samples of blood" and a detailed table putting together the results of a very large number of surveys dealing with hæmoglobin-levels, all of which had been conducted under conditions meeting with the requirements of the Panel. Other tables set out results of surveys showing protein levels in serum or plasma in healthy persons and under conditions of nutritional œdema.

The report ends with details of working methods and a "comparison of results obtained by various methods with those obtained by measurement with other methods used as standards". A list of references is included.

The Food Consumption Panel had a problem of a different nature to face. Provided facilities are available, laboratory investigators have a straightforward job; but dietary surveys are always complicated by the fact that collection of data for analysis depends to a very large extent on obtaining full co-operation from the individuals being surveyed. At the best of times this is difficult to ensure; under the unsettled conditions immediately following liberation of enemy-occupied countries, it must have been still more difficult. Where there are food shortages and the inevitable 'black market', investigators must necessarily be regarded with suspicion, if not with fear. In territories where the administra. tion is in the hands of strangers, the local population is usually inclined to blame them for all difficulties and shortages, and investigators belonging to such an administration may find it virtually impossible to establish the necessary confidence.

The Panel recognized that such difficulties would exist, and it is stated that "investigators should be provided with letters of authority and preferably with a photograph. Arrangements should be made with the local burgomaster and police to establish the credentials of each investigator and ensure her protection if necessary." It would be interesting to know how this has worked out in practice; my own experience is that the more informal and unofficia 
the contact between investigator and investigated, the more readily the information is obtained and the more complete it appears to be.

The Panel proposed that four kinds of dietary surveys should be made-"of (1) the family, (2) individuals, (3) the consumption of individual foods, and (4) institutions and works canteens". Two methods of family studies are described in detail: (a) a questionnaire method, and (b) the log-book method. The first of these is largely a test of the housewife's memory (in addition to her willingness to tell); the second requires her to keep detailed records, with the investigator checking every second day following the initial recording of stores. For individual intake records, a measurement-at-table technique is described.

These methods were used successfully in Britain even during the War, but conditions in newly liberated territories must surely have been very different. The Panel goes on to state that "it is important that sufficient clerical staff is available to keep the analyses of the data well in hand", it suggests that "each household might be surveyed for at least a fortnight and whenever practicable for four weeks", and it talks of a "team of thirty to forty investigators together with four supervisors", and the establishment of a central organisation for Hollerith work analysing the survey data.

The report would, in my opinion, have gained in value if it had included a description of methods which could be applied when such facilities are not available and under conditions where form-filling co-operation cannot be expected (after all, it is not only the illiterate who find difficulty in filling in forms accurately). However, it may be that the Panel-apparently thinking in terms of Europe only-was able satisfactorily to forecast the conditions and facilities which were actually found. It would now be useful and interesting to know.

The report on "Nutrient Values of European Foodstuffs During the War", prepared by the Combined Working Party on European Food Supplies, is included as an appendix.

M. W. Grant

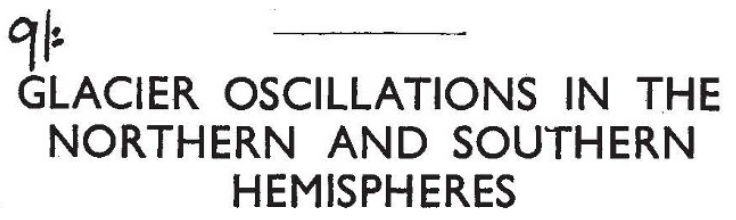

$\mathrm{T}$ HE Report of the Committee on Glaciers for 1945 (Trans. Ame Gegpilys. Union, 27, $219 ; 1946$ ) contains much Mluallis data on glacier variations in the United 1 vitew Jand Peru, together with an outline of the genjeral pattern of glacier histories in the two hemispher.

Prtor to 1850 , European glaciers had been oscillating forward and backward at frequent intervals, the major advances being the greatest since the end of the Pleistocene. Since 1850 , however, recession has been dominant, although interrupted by a moderate re-advance around 1890 and by local smaller advances between 1910 and the early 1930's. The recession has proceeded by successive stages of increasing rapidity, with marked acceleration during the last decade. In the western United States recession has also been dominant since the 1850 's, and although some glaciers made feeble and brief re-advances during the 1920 's and early 1930 's, on the whole the rate of recession has accelerated up to the present time.
The glaciers of New Zealand lost enormously in length and thickness between the 1860 's, when the first observations were made, and the early 1890 's, when they regained much of their volume. Small temporary re-advances have been noted during about 1906-34, but since then the glaciers have again been wasting away, at an increasing rate which has recently been quite abnormal. The Peruvian glaciers have shared an almost parallel history since the 1860 's, again including a phase of accelerating shrinkage since 1932.

Thus in both hemispheres there has been dominant shrinkage during the last eighty or ninety years, with rather close synchronization of some of the variations and especially of the remarkable accelerating recession of recent years.

Among the inferences drawn from the evidence passed in review by the Committee on Glaciers, the following are of far-reaching significance :

(a) The causative climatic variations have affected both hemispheres simultaneously and not in alternation.

(b) It is therefore reasonable to suppose that the more pronounced post-Pleistocene variations and the major Pleistocene variations were also synchronous in the two hemispheres.

(c) Whatever the causes of these climatic variations may be, their world synchronism rules out all 'astronomical theories', such as those of Croll, Spitaler and Milankovitch, that require refrigeration of one hemisphere and simultaneous warming of the other. The mathematical verity of these theories is not impugned, but it is evident that the causes of elimatic change which they postulate are subordinate to other more potent causes, the nature of which is still undetermined.

(d) Calculations of glacio-eustatic changes of sealevel that are based on the assumption of synchronous glaciation and synchronous deglaciation in both hemispheres are essentially sound in principle.

\section{FORTHCOMING EVENTS 싸.}

\section{Tuesday, July 23}

ROYAL ANTHRPgOJOGICAL INSTITUTK (joint meeting with the SOCIETY OF ANTI 6 ARIES OF LONDON and the UNIVERSITY OF LONDON INSTITUT OKC A RH 20 OOGY, at University College, Gower Street, London, W WC.1), (4t 5.30 p.m,-Dr. L. S. B. Leakey: "The Acheulean

\section{Thursday, July 25}

FRITISH 1 spocr prion (joint meeting of Section $\mathrm{L}$ (Education) and the pivision for the Social and International Relations of Science, a the 1 ofal hostitute of British Architects, 66 Portland Place, London, W 1 L Lat 10.30 a.m.-Conference on "UNESCO and Universities". deological Societr of London (at Burlington House, Piccadilly, London, W.1), at 5 p.m. - Prof. Emmanuel de Margerie : "Three (Second William Smith Lecture).

\section{APPOINTMENTS VACANT}

APPLICATIONS are invited for the following appointments on or before the datps mentioned:

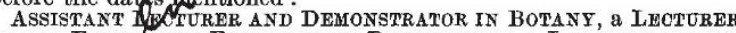
IN THE FLGG RICAL ENGINEERING DEPARTMENT, a LECTURER IN THE Mathen fafos Department, a Senior Lecturer in Production Exulanemring, a Leoturer in the Natural Philosophy DepartMe 2 , and Demonstrators (2) IN THe Department of PHarmacyThe Secretary, Royal Technical College, Glasgow (July 27).

Litorurar IN CHemrsrry at the Coventry Technical College--The Director of Education, Education Offices, Coventry (July 27).

JUNIOR LACTURER IN EleCTRICAL ENGINEERING-The Clerk and Treasurer, Dundee Technical College, Bell Street, Dundee (July 27) SENIOR LFCTURERS (2) IN MATHEMATIOS in the University of Melcourne-The Secretary, Universities Burea11 of the British Fmpire, 24 Gordon Square, London, W.C.1 (July 30).

LECTURER and an ASSISTANT LECTURER IN MECHANICAI ENGINEERING-The Registrar, University College, Southampton (July 31). 